\title{
GHOSTS, TROUBLES, DIFFICULTIES, AND CHALLENGES: NARRATIVES ABOUT UNEXPLAINABLE PHENOMENA IN CONTEMPORARY DENMARK
}

\author{
Kirsten Marie Raahauge
}

\begin{abstract}
Many people experience something that they cannot explain, often they hear something that is not there as a visible fact. The sensation of hearing, for example, someone who is walking through your apartment, when no one is there as far as your eyes can see, poses a problem to the witness, especially if he or she does not think that this kind of occurrence is possible. Based on my fieldwork on haunted houses in Denmark today, this article deals with the narratives of people who have experiences that they cannot explain and that they consider to be on the limits of reason. Many of them do not consider 'ghosts' or 'haunting' as a possible explanation. This causes difficulties when they narrate and contextualise their experience, and typically they present ambiguous narratives and stress their disbelief at and bewilderment with the experiences. Still, as I will try to show in my article, their bewilderment and the way they use the notions 'ghost' and 'haunting' point to possible reinterpretations of these notions, so that the narrative mediation shapes not only the experience but also the ways that 'ghosts' and 'haunting' are reinterpreted in contemporary Denmark.
\end{abstract}

Keywords: anthropology, fieldwork, ghost, haunting, limit of reason, narrative, residual category, sensation

\section{INTRODUCTION}

I had just moved into the old thatched farmhouse. It was situated near a road. When I had gone to bed the first night, I found that the light from the street lamp was shining right in my face. So I jumped out of bed with a sudden move in order to cover the window with a blanket. I think that the ghost was not prepared. I think that it had intended to glide silently through the room. But I jumped right out of bed and bumped into it. That was really a strange feeling. (A woman in her $60 \mathrm{~s}$, narrating about an incidence that happened approximately ten years ago outside Lundby in Denmark $)^{1}$ 
This article is based on my anthropological fieldwork on haunted houses. People's experiences with haunted houses and ghosts in today's Denmark have been in my research focus since 2007. The project is part of the larger research project, On the Limits of Reason (see Jöhncke \& Raahauge \& Steffen 2015). My interviewees talk about their unexplainable sensations as experiences with ghosts, but usually they do it reluctantly, since they are not sure what it was that caused the particular sensation and since they do not consider a 'ghost' a possible explanation. This poses a challenge as to how to tell the story to others and how to explain it to themselves. Furthermore, this brings up a question about the analytical methods of anthropological and related disciplines, as to how to deal with something that lacks social and cultural frameworks in the everyday life of the ones experiencing it. At the same time, the ambiguous use of the notions 'ghost' and 'haunting' in the narratives points towards a reinterpretation of these notions, questioning the framework of 'supernatural' in novel ways. In the following, I will concentrate on this interactive process of experiencing, interpreting, and narrating in more detail and point to some models and features that are especially characteristic of the contemporary ways of narrating about unexplainable phenomena.

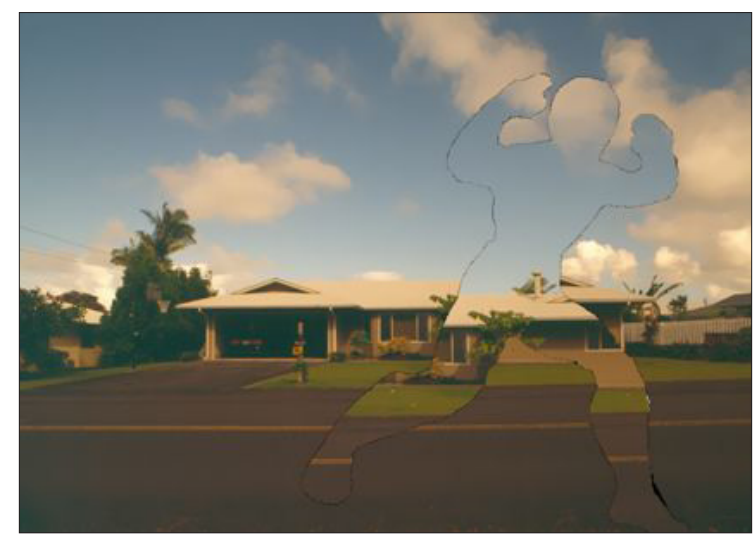

Figure 1. Ivar Tønsberg: Running Spirit. Copyright Ivar Tønsberg 2008. 


\section{FROM EXPERIENCE TO NARRATIVE AND BACK AGAIN}

Many ghost stories are shaped by recognisable narratives, that is, ghost stories from fiction, from the branding of old castles and manors, from children's stories, films, and historical collections. The narratives about unexplainable experiences dealt with in this article are different. They are difficult to understand through recognisable narrative structures and protagonists, and they do not fit well into everyday life, common sense, or paradigms of reasoning, acknowledged by the ones who had the experience; in fact, in their opinion it might not be possible to call them stories. This article is about such ghost narratives; it is about how the ones who had the experience try to fit them into a narrative and an explanatory framework that they might not actually consider adequate themselves.

Gillian Bennett (1999) points to "traditions of belief in story and discourse" (as the subtitle to her book on this subject goes), when she compares the results of her fieldwork among elderly women in England with supernatural traditions. England and Denmark certainly differ, also when it comes to the position of 'ghosts', but it is still rather striking to find such a large difference in the naturalisation of supernatural cosmologies between these two regions. The same point has been made in Ülo Valk's article, Ghostly Possession and Real Estate (2006); here Valk explores the relations between narrations about ghostly experiences, beliefs in ghosts, and the way they are connected to specific sites of real estate and certain family relations. Valk's study builds on the fact that ideas about ghosts can be understood as related to reinterpretations of belief systems in the contemporary society of post-Soviet Estonia, and his material shows that ghosts can be experienced as possessing real estates of families. As Valk writes, his "article illustrates the ability of legends to adapt to history and to provide meaning in a chaotic social environment" (Valk 2006: 33). The reappearance of ghosts is interpreted as their reaction against modern times. Valk writes:

Keith Thomas, who has studied popular religion in early modern England, has written that "the main reason for the disappearance of ghosts is that society is no longer responsive to the presumed wishes of the past generations" (1971:723). Amazingly, the reappearance of ghosts in Estonian folklore seems to have the same meaning: the discrepancies between the values of modern people and past generations make the dead restless. (ibid.: 47)

This fascinating analytical point implies that in contemporary legends the dead are taking action according to value shifts, and that these actions are recognised by the living. Valk shows how the dead are understood as related 
to traditional ideas about ghosts, family relationships, and ownership of real estate. Both Bennett and Valk display material in which it is possible to understand experiences by way of their context - be it of tradition or of a societal shift. This is rather different from what I encounter in Denmark, since many of the relations that are pointed out in these two studies are not relevant to the Danish interviewees.

Often my interviewees do not know what to do with their experiences; they do not have a stable framework that could induce their sensations with meaning, and their efforts to narrate about them merely accentuate the fact that they cannot fit them into a coherent narrative. Furthermore, this problem is reflected in the analytical process; anthropological perspectives can shed light on the context of the ghost story, but when the narratives point out that there is a gap between context and experience, this gap becomes the main focus of the analysis. The ghost itself slips away, since we only have the story told about the experience. What is at stake here is that the narrative about the experience tends to become ambiguous for the narrator as well as the anthropologist.

\section{ANALYTICAL FRAMEWORKS}

The difficulty with narrating these kinds of experiences is related to the lack of connection between the out of place experience and the common sense explanations and reasoning available, as seen from the narrator's point of view. ${ }^{2}$

This challenge is also reflected on the analytical level of understanding the context in which this field is embedded; when something is easily connected to background perceptions, concepts, social relations, etc., there is no reason to question these background frameworks. On the other hand, if these connections are difficult to establish, the challenge goes beyond the narrated experience, and also involves the very context from which it seems to be isolated. From the 1980s onwards, concepts such as 'culture', 'cosmology', 'society', 'imaginary' and 'religion', as well as 'nature', 'supernatural' and 'belief', for that matter, have been deconstructed and contested, criticised for essentialism and accused of describing academic ways of thinking far more precisely than the empirical field. So what concept might then be used for this background setting? When referring to 'common sense explanations and reasoning', I wonder whether these notions solve the problem of the ill-reputed, criticised, and deconstructed concepts mentioned above. Who knows what is the 'background framework' or 'common sense' or 'reason' of any 'culture'?

This problem is also identifiable in Émile Durkheim's "collective consciousness" (1997 [1893]), a concept that has been criticised for hypostasising frag- 
ments of empirical observations to a theoretical assumption that might have more to do with Durkheim's theory than with the empirical field where the fragments were observed. Such notions serve as phantasmagorias of intellectuals, explaining coherencies that might not be there, if it were not for these concepts.

The challenge is immanent in Western philosophy as such: here the stable categories of systematic thinking are flawed by the stability offered by this philosophy, a point that Jaques Derrida has made very strongly. Therefore, the seemingly aimless and nonsensical aspects of the narrations of my field are highly relevant seen from the deconstructive perspective of Derrida. In Specters of Marx: The State of the Debt, the Work of Mourning, and the New International (2006 [1993]) Derrida establishes a 'hauntology', aimed at criticising the ontology of Western philosophy. This rigid definition-ridden monolith is not capable of understanding the phenomena and processes of the world it seeks to describe, so in order to permit the floating, changing world we inhabit into the language of philosophy, Western ontology should be replaced by a 'hauntology'. The ghost is a perfect metaphor for this philosophical problem; it plays the role of the 'Thing'3 (ibid.) that slips away from theoretical systems. The 'Ghost' of Derrida slips away from the systems of Western philosophy, but empirically it is still there, as the 'Thing' that moves beyond the systems.

In my empirical field the ghost is present as an experience that was really sensed, but the same ghost slips away from the systems of explanation; it is the unexplainable sensation that puzzles the person who sensed it, as well as the anthropologist. Furthermore, this problem is detectable only through the narrative about the experience, labelled as 'ghost', but at the same time this very notion is questioned when the interviewees distance themselves from the fixed category of 'ghost'.

Post-human theorist Bruno Latour gives another perspective to this discussion. In his Why Has Critique Run Out of Steam? (2004) Latour addresses the problem related to the methods of social scientists, positioned as critical intellectuals. In that role they point to something behind the phenomenon in question in order to explain it. They point to the phenomenon either as a 'fairy' or as a 'fact'. When the phenomenon in question is seen as a 'fairy', the argument goes as follows: "The role of the critic is then to show that what the naïve believers are doing with objects is simply a projection of their wishes onto a material entity that does nothing at all by itself" (ibid.: 237). If they understand the phenomenon as a 'fact', something else happens, in order to reach the same goal, of course, of being a critic:

This time it is the poor bloke, again taken aback, whose behaviour is now 'explained' by the powerful effects of indisputable matters of fact: 'You, ordinary fetishists, believe you are free but, in reality, you are acted on 
by forces you are not conscious of. Look at them, look, you blind idiot' (and here you insert whichever pet facts the social scientists fancy to work with, taking them from economic infrastructure, fields of discourse, social domination, race, class, and gender, maybe throwing in some neurobiology, evolutionary psychology, whatever, provided they act as indisputable facts whose origin, fabrication, mode of development are left unexamined). (ibid.: 238)

In the first case the critical intellectuals neglect the real subject matter in order to search for projections; in the second case they also neglect it, this time in order to explain the factual reality behind what is thought to be something else. This method, Latour argues, leads to a blindness concerned with real phenomena, and he advocates for going from 'matters of fact' to 'matters of concern' in order to grasp the phenomena in their own right. This critique and cure has proven relevant in my field (see Raahauge 2015). ${ }^{4}$

Derrida and Latour both shed light on my problems within the field of ghost narratives. On an empirical level as well as theoretically the ghost escapes out of the narrative, because the focus tends to be on the reasons for, the background of, the connections to, or the representation of something else (Latour), or on possible notions available for describing the idea it represents (Derrida).

In his article titled An Experience-Centered Approach to Hauntings, James Hufford points to the challenges arising from this dilemma from quite another angle. His phenomenological approach points at the distance between experience and cultural background. "[I]f the phenomenology of core experience is genuinely independent of cultural background, then these experiences cannot simply reflect cultural meanings" (Hufford 2001: 20), he states, thus bringing to the fore the ontological status of the experience. Hufford is also interested in the interplay between the absence and presence of relations between the experience and its background. In the introduction to the anthology, Haunting Experiences: Ghosts in Contemporary Folklore, Hufford's position is stated very precisely:

Central to this move toward the ethnography of belief is the work of David Hufford, who developed what he termed the "experience-centered" approach. Hufford's work is heavily phenomenological, focused on the relationship between experience and the supernatural, and based on the premise that stable and consistent features in narrative and reported tradition may, in fact, suggest actual experiences, accurately observed and interpreted rationally. (Goldstein \& Grinder \& Thomas 2007: 14)

In this line of thought, the real experience tends to escape the analytical gaze, because it is interpreted in an unproductive manner. Hufford thus suggests focusing rather on the experience, not the background, and he does this in 
a thorough and methodological manner. He suggests an experience-centred approach for accessing the field. This discussion of a possible distance between the experience and the context (from Derrida through Latour to Hufford) gives me an impetus to start with recognising the sensation referred to in the narratives of my interviewees instead of pointing to projections of a psychological state or some other trope for explaining it away. Something happened to someone.

In spite of Hufford's endeavour, some parts of the experience might be difficult to grasp, precisely because the analyst and the interviewee do not share the experience in focus, as Richard Baxstrom argues. Baxstrom has dealt with similar problems within anthropology in his article Knowing Primitives, Witches, and the Spirits: Anthropology and the Mastery of Nonsense (2014). He explores the rationalities behind anthropology, and states:

As such, it is my argument that social and cultural anthropology's felicity as a science is predicated on rationally mastering such invisible, irrational forces via the techniques of ethnographic field research [footnote taken out by the author]. Or, to use Strauss's term, anthropology developed as a distinct human science via the desire to credibly master nonsense. (ibid.: 5)

Baxstrom points to the fact that anthropologists are reluctant to explore invisible phenomena or take them seriously. Hereby important parts of the field disappear. Furthermore, anthropologists rely on fieldwork to provide the right empirical pieces of information. In that sense anthropological methods are much like the methods of the witch trials of the 16th century, Baxstrom argues: the system (based on the judgement visible or invisible) decides what is considered real (to the theological experts partaking in the trial at the witch craze, or to the anthropologist today), not the phenomena that surround us (part of the field). Baxstrom writes:

This tie between mastering what Strauss has termed 'nonsense' and scientific authority has its roots in transformations that occurred in the course of the so-called 'witch craze' in Europe in the sixteenth century regarding what constituted evidence within the overlapping institutional domains of science and law dominated by an active theology of the real. (ibid.: 8)

In this light, opening up to the idea that not only phenomena that the anthropologist might see as empirically verifiable facts might be part of the field (an opening that both anthropologists and the people who have experienced haunting have difficulties administering), we will now turn to the question of how narratives shape experiences. ${ }^{5}$ 


\section{THE SETTING OF THE SCENE: TIME, SPACE, AND ACTORS}

On a weekly basis, steps were heard on the staircase by the inhabitants of a house in Nørresundby. Normally the steps stopped halfway. The staircase was empty every time they checked on it. They also witnessed series of other experiences, but they did not tell anybody, since they knew that they would be looked upon as weird, if they told others about their experiences. Eventually they moved to a larger house, and when they came back, their neighbours said that the new inhabitants were crazy, they heard strange steps on the staircase and other weird stuff.

These kinds of narratives are rather typical of my material. It is common that a person hears somebody walking on the staircase, but cannot see the one who is walking, or a person might see someone standing at the fireside, but cannot hear or touch the person. In other words, my material often contains descriptions of experiences that do not involve all the senses; typically, the experiences are connected with hearing something that seems not to be there, because the person cannot see it.

Extraordinary experiences described in my material are usually of a limited duration; they mainly take place unexpectedly at some point of the day, and only in rare cases they occur repeatedly. The narratives often question the reality of the experience, and in that way the narrator is in a position of suspense, waiting for a possible next experience to confirm the reality of the first one. Thus a new experience, maybe in the form of a repetition of the first one, could help the narrator to recognise that it actually happened for the first time. This does not add to the comprehensibility of the incidence, though.

Space plays a role as a static scene; typically, the narrator points to certain places; in most cases the experience does not transgress one place or follow the narrator around. Instead, it seems that the narrator and the ghost should be at the same place at the same time in order for the experience to occur. In many cases the presence sensed seems to be in a room next to the narrator, typically staircases or corridors, or it has an impact on a virtual channel such as a computer, iPad, TV, or DVD-player. It is not seldom, though, that the narrators have sensed the presence of something that is quite near to them, in the same room. As an example, one might point to the following narrative, told by a woman who had a series of experiences in a house that she and her family had lived in. One of her experiences took place in the cellar, where she was hanging laundry up to dry. Sometimes she sensed the smell of a drunkard. The smell followed her closely as she moved, but she could not see the person. Her husband experienced the same, and he also heard a deep humming sound as if from a person, a loud "Mmmmmm". 
The actors of the narrative involve, on the one hand, the one (or the ones) experiencing the ghost and, on the other hand, the ghost (or the ghosts) - "or whatever it is" - this is a remark put forward by most of my interviewees. Since the ghost is dependent on someone experiencing it, it plays a passive role of becoming visible or audible for someone; it is only present through the person who experiences it. At the same time, this person often thinks of himself or herself as a passive victim of the ghost that appears, and thereby actively intrudes into the life of the person. It feels as if the ghost and the one experiencing it do not share the same context, or, as one interviewee told me, it is as if the ghost suffers from 'contextual autism'. Additionally, the narratives often stress a sensation of suddenly being in the middle of an unknown story or scenery. The narrator has experienced a fragment that needs some kind of framework in order to become understandable; it is as if it is out of context on purpose. Furthermore, because the emanation of the presence of the ghost is perceived by only some of the senses, the witness is restricted in the sense that he or she is blind to something he or she hears, or cannot feel something he or she smells. So, because of the limitations in time, space, and sensations, this kind of narration describes what might be termed Limited Emanation of Presence (LEP) (Raahauge 2015). The point made by Hufford (2001) is near to these observations and also his technique is close to ethnographic methods when interviewing and analysing data.

\section{NARRATIVE GAP}

Most of my interviewees use the notion 'ghost' without believing in ghosts (see also Raahauge 2015). They use the word as a residual category, since no notion seems to cover their experiences. Often they are explicit about the contested nature of the notion. One might say that the residual category shows that there is a system, but also that the ghost experience is not part of it, hence the narrative points to the cracks and fissures of its own premise - that is of 'ghost' as a category. "Dirt is the by-product of a systematic ordering and classification of matter, in so far as ordering involves rejecting inappropriate elements", anthropologist Mary Douglas explains (1966: 44), thus coining the term 'matter-out-of-place', and pointing to the structural significance of things that one cannot put into a well-established order, be it dirt or ghosts.

Many of my interviewees point to the fact that it is difficult to narrate something that they do not know. This narrative gap is explicit in my material, as many interviewees state that concepts such as 'haunting' or 'ghost' are used in their narrative in order to categorise personal experiences of confusing, uncon- 
trollable, inexplicable, and matter-out-of-place phenomena. They are troubled by the lack of correspondence between the experience and its context, and also by the difficulties connected to mediating and thereby forming the experience through a narrative.

Since it is rare, even considered a bit ridiculous, by most of my interviewees to accept other kinds of beings than the ones that a person can empirically observe, the sensation of something that a person cannot explain puts him or her into a position of brief existential confusion and sometimes also a long-lasting social embarrassment. ${ }^{6}$

As touched upon earlier, the matter-out-of-place character found in my material is different from some of the other recent studies in the same field. Some studies point to tradition, as does Bennett, or coherence with societal shifts, as does Valk; others point to a negotiation according to the belief system, as does Cowdell (2011). After having explored several aspects of the belief systems available, the latter writes:

We have looked from several angles at the relationship between experiences and the expressive form given them when they are discussed, and how this intersects with belief. This research prompted oral and written stories, allowing an assessment of how these interact, and how oral narrative negotiations of supernatural experiences and belief work today. A straightforward connection between report and belief, or experience and belief, is commonly posited. The evidence points instead to their complicated negotiation. (Cowdell 2011: 88)

This negotiation might take many forms, but in the process the narrative is used to suggest contexts by the interviewees, and also by the folklorist. Also Jeannie Banks Thomas points to relations between context and experience to be traced in the narrations, not as a matter of belief, but rather as a way that ghost stories are used to make sense of the world. In "The Usefulness of Ghost Stories" (Thomas 2007), a chapter in the anthology titled Haunting Experiences: Ghosts in Contemporary Folklore, she writes:

In this chapter, I emphasize that there is much more to the realm of the supernatural than questions of belief, and I argue that ghost stories are a useful way to come to a better understanding of the worlds we inhabit. I present several ghost stories and describe a range of ways in which the narratives help us look more closely and analytically at culture, the environment, and the personal. (ibid.: 26)

Thomas has an important point in stressing this relation between the ghost stories and the world we inhabit, and also in pointing to the aspects that are 
not connected to belief. However, in my field, the usefulness of ghost stories is rather a matter of coming to terms with the absence of meaning or relations in the world we inhabit. I only seldom find structures or relations that connect the narrative to the context. Instead I find interviewees who point to a lack of connection. One might say that to a large degree we share method and topic, but the material differs.

\section{SOMETHING THAT ONE DOES NOT KNOW}

The notions 'haunting' and 'ghost' point to ideas about life and death that are not common among my Danish interviewees. The notions are somewhat out of date, and not many of my interviewees believe for real in the possibility of dead people (or animals, for that matter) re-emerging as something one can meet in daily life. This line of thinking is typically considered to be a bit ridiculous, superstitious, and certainly belonging to the past.

Ghosts have been connected to various narratives in Danish folklore: people come again as ghosts after death, because they want to convey a message; people have become 'ghosts' because of the way they died, or the way they lived. ${ }^{7}$ These interpretations might have a normative bias, telling the story about how bad things might end up for people if they behave in certain ways. Many ghost stories are connected with old castles and manors (see Benzon 2006, 2007). So, attached to the notion, an outdated but stable narrative and a general set of ideas are at hand. There is normativity, site-specificity, and a cluster of specific imaginaries connected to the notion. Today these ideas of 'ghosts' can mostly be found in global narratives created by entertainment industries, fantasy literature, and films, as well as children's tales, as Bennett also points out (1999).

Despite of this distance towards 'ghosts', many of my interviewees use the word 'ghost' when they narrate about their personal sensations. This gives the narration a direction that opens up for the possibility of dead people rising again, echoes in the wall, and shadows of something that is not there to be seen. Although they use this word for lack of better ones, and although the term 'ghost' has no resonance in their everyday world, in some ways the word 'ghost' does correspond with some of my interviewees' tentative explanations. The use of the word 'ghost' increases the possibility that maybe, in fact, it was a ghost after all - an idea they often point to not having had before their experience, and furthermore, a rather vague idea about the content of a 'ghost'.

Thus, on the one hand, most of the interviewees find it important to point to 'ghost' as a problematic term, and, furthermore, they are not pleased to use an outdated word that represents a way of explaining that they do not find 
realistic. On the other hand, they still had the experience, and in some ways it does come close to what used to be known as a 'ghost', and the notion has a suggestive force that might interpret the experience in some direction, although as a starting point they do not believe in ghosts. The situation is ambiguous.

\section{NARRATIVE BRIDGES}

This ambiguity has a destabilising effect, as focused on until now, but it also has a stabilising potential. The narratives produced do not mediate the experience entirely successfully; they rather narrate about their own gaps and cracks. Yet, at the same time, the narratives can also produce bridges. Most of the narratives I have registered are concerned with hearing footsteps or slamming doors or keys in the keyhole or somebody on the staircase; this often happens without any acknowledged connection to the context in which it takes place. In order to discuss how my interviewees have tried to connect their experiences with some framework by way of their narratives and to show varying degrees of elaboration of the ghost experience, I will present some examples of different kinds of ghost narratives from rudimentary over fragmented to almost coherent narratives. These variations of the narrative are connected to the character of the experience, but simultaneously the experience is also shaped by the narrative. The three text examples represent one possible way to discuss narrative strategies; it is not a fixed set of categories that all narratives can fit into.

\section{RUDIMENTARY, FRAGMENTED, AND ELABORATED NARRATIVES}

The first example illustrates what might be thought of as rudimentary narratives.

On that spring evening I was alone in my large flat. I was working with some archives in a small room when I heard the sound of footsteps in the passage that runs through the flat. I thought it was a burglar, so I hurried out in order to stop him. No one was there. I sat down in the room again and started working. Once more I heard the sound of footsteps and went out to see who it was. No one was there. The third time I went through all the rooms in the flat, opening and locking all the doors and windows and also the doors of the closets, cabinets, and cupboards - in vain. The fourth time I asked myself if I was in some weird state of mind that could 
account for my hearing this - also in vain. When I heard it starting all over again, I hurried out and went to a pub. (A man in his fifties, now a director of a large company, about an incident that happened to him some thirty years ago in a large old flat in Copenhagen.)

These kinds of narratives are rather frequent in my material. There is a distinct sound that cannot be explained away, but the narrator cannot connect it with other parts of his life either, because he has no reference or clue about how to do it. The narrator of the cited story points to two filters he has used: something outside himself, in the physical world, and something inside himself, a state of mind. After not having succeeded to filter the incident into its right place, he gives up and leaves. His narrative is vague, only pointing to the fact that he had the experience of the sound of steps from a human being in the corridor while being alone. The narrative from Lundby about bumping into a ghost (cited at the beginning of my article) is also an example of a rudimentary narrative, but in this case the experience has at least motivated the narrator to talk to her neighbours about the incident in order to find out whether it should be understood as a ghost, a dead person, or a former resident of the house, and if so, who it might be. The narrator thinks that if it is a former resident, it must be benevolent, and, furthermore, it might be a woman. This is the start of forming a fragmented narrative, in connection with the neighbours' possible evidence.

A fragmented narrative is somewhat more coherent, as in the following example, told by a man in his forties, now a university professor and head of department, about an experience that happened to him approximately 20 years ago.

At a dormitory in Copenhagen a young man had gone to bed after having locked his door as usual. He lay in his bed without being able to sleep and watched the yellow light from the busy street outside the window. Then he heard the door opening and the sound of steps coming towards him. He did not dare to turn around to see who it was, and as he lay in his bed without being able to get away, he felt a coldness surrounding him. He lay there for maybe half an hour before he managed to fall asleep and in that way get away. After his experience the man heard a rumour about a girl who had committed suicide by jumping out of the window of her room many years ago. After having talked to me, he was invited to a gathering at the old dormitory, and there he tried to establish whether the girl had lived in his former room or in another room - but in vain.

This example of a fragmented narrative has similarities with some other narratives in my material; for example, the way that the interviewee tries to make sense of his experience. The fragmented narrative still raises suspense: will the man ever find out what happened and why it happened? This suspense 
has intensified due to the interference of the anthropologist making him into an interviewee who starts registering and analysing the incident anew.

The form of an elaborated narrative is extraordinary among my material, because it is seldom that these kinds of narratives can actually be told coherently. The following happened approximately eight years ago in a small town just outside Århus, the second largest city in Denmark.

The woman who told the story started out telling me that it often happened when she was sitting in the TV-room, an extension to the house that they had made. She was sitting in front of the TV and then, out of the corner of her eye, she saw this black smoke. It disappeared when she focused on it. That happened more and more frequently. Her daughter started to receive strange messages on her mobile phone, and as finally it became too much for her, she told her husband that she would try to find some kind of clairvoyant or house cleaning specialist or whatever it is called, in the yellow pages. Her husband said that it was idiotic to pay for that kind of service. It turned out that he had also had a series of experiences, with a man in a tuxedo. And her husband knew who it was; namely, the former resident that they had known. He used to perform as a magician in his tuxedo, and now he was in the TV-room still wearing it. One day, soon after she had said she would get rid of the strange experiences with the help of some professional, her husband went out to his Citroën, called the magician, opened the car door and asked him to get in. Then he closed the door again and drove away. A couple of kilometres away the widow [of the magician] lived; there he stopped the car, told the magician that his wife lived there, and asked him to get out. Afterwards he told his wife what he had done. She did not really believe his story, but a couple of weeks after the car drive, she met her old friend, the widow. The latter told her that her deceased husband had paid a visit to her on that very same day. Only after that did she tell her old friend, the widow, about the car drive. After all this the house had no apparitions, smoke, or malfunctioning mobile phones. (Told to me by a woman in her forties, who currently holds a leading position in the economical administration of a university and is a mother of two, about an incident that had recently happened to her family.)

The interviewee and her family had no prior experiences; only this particular house had caused problems. These experiences were not part of the family's everyday life and ghosts were certainly not part of the way the family would normally explain things. It came as a surprise to the woman that the car ride had an impact, and, furthermore, this opened up possible new horizons of what she might believe to be happening. As it seemed to have an impact, the woman saw herself forced to accept some ideas not acceptable to her normal way of 
reasoning. When her husband offered the ghost a car ride, he might have pondered about it already for some time.

This experience is shaped by the actions of the husband, which point to some ideas about the deceased wanting to get into contact with their kin, thereby indicating a connection to the ideas about kin, but in a new and not culturally accepted combination with the dead persons having agency. This stabilises the events into a narrative linked to a background context. Also the story in fact has a beginning, suspense, crescendo, and end, time, space, and actors. The only problem is that the woman does not believe in this narrative: she believes that she and her family experienced something, but she has a hard time believing that the narrative is true. The more extended the narrative becomes, the more there is for the woman to accept it as a fact: the narrative that explains the experience unavoidably also expands the frames of her acceptance.

The narrative is extraordinary in comparison with other narratives in my material, due to its coherency, and also due to the implicit suggestions about life after death and feelings between spouses beyond life and death. It is also outstanding for the reason that the history of the house can be easily associated with the experiences of its inhabitants. To the woman's amazement her strategy of reasoning, to uncover the kin relations formerly linked to the house, seems to work, and in a way the experience can be explained. If one accepts the idea that spouses can meet after the death of one of them and that one can talk to the deceased and take them for a car ride, this is a perfectly logical explanation. If not, the connection to earlier events in the house, to the magician and his widow, might seem even more confusing: in addition to being forced to take seriously the sensations experienced, the narrator now also has to believe in an explanation involving ways of reasoning rather unfamiliar to her. ${ }^{8}$

\section{MAKING SPACE FOR SOCIAL UNDERSTANDING OR AVOIDING AUDIENCE}

In order to transform the matter-out-of-place experience into an in-place experience, one needs a confirming audience. And since ghost stories are often ridiculed, this might be difficult to achieve because the ones who have had the strange experiences perform self-censorship or are laughed at when they break the taboo and tell someone about their experiences.

The following story was narrated by an academic in her late forties, mother of two children, about a woman who often sees an elderly woman here and there in her home. When the Hoover is started, she stands at the top of the stairs and scolds. Her grey hair is bobbed, and her apron and dress can be described 
in detail, with patterns, colours, and accessories. She is the former resident of the house and the woman has asked her neighbours what she was like (fuzzy) and what she looked like (grey bob, apron, etc.) in order to silently confirm her suspicions. But she would never tell anyone about her ability to sense dead people and other supernatural experiences: "This is not the visiting card I would throw," she says. Like many others she faces the isolation of not being able to tell anyone about her experiences (or she reveals them only to a few). She has had many contacts with supernatural beings, like ghosts or spirits, and sometimes she also knows their origin.

It is clear that such personal sensations only seldom correspond to the common-sense reasoning or the rationalities that the interviewees consider reasonable. The explanations at hand are the ones that are concerned with projecting the focus from the actual incident to the person experiencing it (like the ones enumerated by Latour). This kind of explanation, be it a 'fact' or a 'fairy', is not accepted by the interviewee in the last example; nor is it by any of those I talked to. They would have liked to project the experience onto something else, yet found it impossible; therefore others who do so cannot convince them either. This last challenge concerns the trouble of telling other people about something that is collectively thought of as a ridiculous superstition from the past. Only on very rare occasions such narrating is done successfully.

\section{DEATH AS THE IMAGINARY}

Most of the narratives are rudimentary or fragmented, and the connections made are shifting and not coherent, although the narrators make an effort trying to find some kind of common sense or rational explanations; however, there is still some resonance with traditional supernatural explanation models. As we saw in Valk's article, the Estonian legends reinterpret belief systems; in my case it is not systems but rather notions that are reinterpreted, and this makes the situation here more fragmented than in Valk's - and Bennett's - material.

To some extent the interviewees derive explanations from narratives connected to scientific rationalities (as, for instance, undiscovered phenomena associated with atmosphere, allusions to past errors concerning phenomena that have later been explained by natural sciences), concrete explorations (such as explorations at municipalities, telephone companies, neighbours, or - in rare cases - even clairvoyants), and collective evidence (by way of telling and listening to stories, finding that they are not alone with their experiences). Furthermore, and as another strategy, a direct connection might be made to the deceased. Inexplicable experiences tend to be called 'ghosts' or 'haunting', 
not because the Danes necessarily believe in ghosts ${ }^{9}$ - as already mentioned, most of my interviewees do not - but because there is no other notion available. 'Ghost' is a notion used to point to inexplicable experiences and thereby a residual category rather than a category in its own right. However, the notion also frames the incidents in a certain way; it helps to create a background narrative about shadows or imprints of dead people, or maybe the deceased coming to pass a message. The idea of ghosts might have been abandoned by most Danes years ago, but it is still used, albeit in a new framework and with a slightly different and less stable meaning. 'Ghost' is thus not understood as a common notion one can refer to in order to point to an experience so that everybody would know what the narrator means, but it is rather understood as a vague and undecided word for a shadow that is maybe left by a dead person. The word 'ghost' may be still used as a notion with an implicit, albeit vague, narrative, although it is contested in all possible ways, by the person sensing it, by the people hearing about it, and by the narrative used to mediate the experience and fit it into everyday life. In Valk's Estonian material (2006) the reinterpretation of traditional belief systems is much more successful because here ghosts are connected to real estate through elaborate systems of relations; yet, in my field it is often only a matter of some kind of vague idea about life and death.

If there might be some truth in the idea of ghosts after all (you never know!), there is at least an idea, and thereby if not an explanation, a vague narrative to mediate and maybe stabilise the experience. There is narrative glue and some ideas to connect to - only the narrative is still ambiguous. On the other hand, the narrative might have glued it all together precisely where the uncontrollable, invisible part of the experience used to be. In other words, did the nonsensical aspect of the narrative slip away again?

By using the words 'ghost' or 'haunting', the interviewees keep the backdoor open: they might not be understood as 'ghosts' in the way we imagine that people once believed in ghosts, but as a potential. Thus the concepts are both empty (a residual category) and in resonance with possible ideas about life and death and the idea that there might be 'more between heaven and earth' than one can explain through acknowledged ways of reasoning. In this way the narrative contains an open-endedness. 


\section{BACK AGAIN}

When a person lives in a society that seeks empirically proven facts, it might be scary for him or her to perceive a crack in this habitual way of reasoning and only be able to establish a fragmented or broken narrative that one is uncertain of, instead of a stable narrative that would fix and add to one's common repertoire of explanations. Yet, on the other hand, it might also give an intense sensation to conceive in a glimpse that we cannot explain everything and that the world might be much larger than we can possibly ever imagine.

Thus the narratives connected to 'ghosts' tend to function as a resort of possibilities and potentials - and the inexplicable phenomena might be thought of as a door into new and puzzling, yet powerful worlds. This is related to the double nature of both presence and absence they manifest - an absence of explanation, of cohesion, of meaning, and of control, combined with a presence of intense, personal sensations and possible new horizons.

The narrative stabilisation of ambiguous matter-out-of-place experiences might not be successful. However, this very lack of stabilising forces has some other effects: for the anthropologist it points to the blind spots of the analytical gaze: as Baxstrom stresses, it is a biased gaze that is reluctant to explore the field on its own premises. This is an important insight that is part of a movement towards ontological discussions within the humanities rising in these years. Furthermore, these non-stabilising narratives point to the fact that the world is not stable: when trying to explore a part of it, one may realise that one's perspectives on the world are not capable of establishing an explanation of everything. If you find that something is beyond your stable categories and not accessible to your analytical gaze, and if you find that this challenge is also very much present for your interviewees, making it difficult for them to establish a narrative that would explain their experience, this is certainly a challenge. However, it is also a way to open up for new and less controllable perspectives. For the interviewees it has to do with reinterpreting the notions 'ghost' and 'haunting' on contemporary premises, allowing them to signify something more remote and vague than they used to do. In my material the reference to a specific idea about ghosts being normatively, culturally, socially, and existentially categorised is replaced by a notion of the ghost as just another word for sensing something that one is not sure of, a sign that the world is larger than one would have expected. For the analyst it is related to reinterpreting the stable understanding of science, allowing it to let something remain beyond the limits of reason.

One might say that the imagination does not give rise to ghosts, it is the other way round: ghosts have an impact on the imagination. 


\section{ACKNOWLEDGEMENTS}

I am grateful to the Danish Research Council for their generous grant that made the research project possible. I also wish to thank Adam Grydehøj from Islands Dynamics for organising the conference in 2015 that brought me into contact with the editors of this volume of Folklore: Electronic Journal of Folklore, and also the editors for arranging a fantastic seminar on the uncanny in the same year. Furthermore, I would like to thank my peer reviewers who suggested many interesting perspectives on my field, as well as Kirsten Møllegaard, scholar of English literature, for her generous reference to works on ghosts globally, and architect Susanne Eeg, who helped me with all the difficulties with the computer.

\section{NOTES}

1 Due to the length of transcriptions I have found it necessary to make summaries in the third person of some of the narratives. This, of course, is problematic since it distances the reader from the narrative; it has been done only in cases where the point to make did not rely on the 1st person representation. The example texts are from the author's archive.

${ }^{2}$ In order to overcome this difficulty, I have also tried to use the notion 'cultural imaginaries' both in this article and elsewhere in order to explore the relevance I found it had, after a session at an EASA-conference in Tallinn in 2014, where I gave a paper at a session called The Edgy Northern European Imaginaries. I tried to use this concept, since at that session I realised that it might be of relevance: in anthropological thinking, however deconstructed, there is a background hypothesis of a shared set of ideas. Sometimes language is stressed; it might also be culture, norms, identities, or values, or it might be shared life worlds that are pointed to, in order to be able to have a point from where you analyse your field. This is unavoidable, so it might be more honest to suggest a position. This, however, has caused more confusion than clarity, so I refrain from using such notions. The point inherent in the background logic could be exemplified through the (rather Saussurean) hypothesis that there is a kind of connectedness between people that is not empirically visible, and that this connectedness is floating and changing. It is detectable only through its effect: it being possible for us to understand each other. This is not the conclusion but rather a condition for being able to interpret the empirical phenomena as something that is shaped in this or that specific way. In this specific context, what is today understood as unexplainable phenomena has been easier to understand through a common background or connectedness of a sort in the not so remote past. For some people at least, a 'ghost' has been a possible explanation for strange incidents. Science as a new system (admittedly, also aging) of belief, or technology (especially the development of electric light) as a force that has the dissolution of creatures of the shade as a side effect of course add to this change. 
3 The 'Thing' is one of Derrida's notions for 'Ghost', i.e. for the phenomena that the Western ontology cannot grasp.

4 I am grateful to Steven Shapiro for suggesting that I considered Latour's take on this problem in connection with ghosts.

5 In this article I will not go further into this discussion. The references to Latour, Derrida, and Baxstrom serve to point to a possible theoretical opening that lies in critical, reflexive anthropology, such as Baxstrom's, and in deconstruction and post-human theory (see Raahauge 2015 for a further discussion of, among others, Derrida and Latour, in connection with ghosts). I wish to thank Richard Baxstrom for inviting me to a seminar on 'the invisible' at the Department of Social Anthropology at Edinburgh University in 2015.

6 I ask about ghosts in all kinds of settings, and in the Danish context my estimate would be that one in every five to ten persons can point to an extraordinary experience, while at the same time only few believe in ghosts.

7 In Danish a 'ghost' is called spøgelse, 'haunting' is called hjemsøgelse. Other Danish words for a ghost are genganger and genfærd, which mean "he who walks by again" and "he, who travels again", respectively.

8 The idea of the stabilising effect of the narrative is congruent to Lévi-Strauss' idea of the house as a transfixer and stabilisator. Carsten and Hugh-Jones discuss this Lévi-Straussian argument of houses, stating: “'Transfixing' an unstable union, transcending the opposition between wife-givers and wife-takers and between descent and alliance, the house as institution is an illusory objectification of the unstable relation of alliance to which it lends solidity (1987: 155)" (Carsten \& Hugh Jones 1995: 8, see also Raahauge 2007).

9 To talk about 'Danish ghosts' is a difficult way of conceptualising the field, since it essentialises the topic by pretending that you can, in fact, point to a difference between ghosts of different countries, for example, Danish and Estonian ghosts, as though they were well known entities that stay behind the borders of the countries and as though they haunted and behaved in ways that you can foresee. This is of course problematic, but it arises from another problem, namely the even larger impossibility of studying 'the global ghost'. Furthermore, it touches upon the problem of essentialising people and places at large, beyond ghosts.

\section{REFERENCES}

Baxstrom, Richard 2014. Knowing Primitives, Witches, and the Spirits: Anthropology and the Mastery of Nonsense. Republics of Letters: A Journal for the Study of Knowledge, Politics, and the Arts, Vol. 3, No. 2, pp. 1-22. Available at http:// arcade.stanford.edu/rofl/knowing-primitives-witches-and-spirits-anthropologyand-mastery-nonsense, last accessed on May 4, 2016.

Bennett, Gillian 1999. Alas, Poor Ghost! Traditions of Belief in Story and Discourse. Logan: Utah State University Press. 
Benzon, Gorm 2006. Spøgelser og Sagn fra danske Slotte og Herregårde. Bind 1: Nord- og Midtjylland. [Ghosts and Legends from Danish Castles and Manors. Volume 1: The Northern and Middle Part of Jutland.] Vejby: Askholms Forlag.

Benzon, Gorm 2007. Spøgelser og Sagn fra danske Slotte og Herregårde. Bind 2: Syd-og Sønderjylland samt Øerne. [Ghosts and Legends from Danish Castles and Manors: Volume 2: The Southern Part of Jutland and the Islands.] Vejby: Askholms Forlag. Carsten, Janet \& Hugh-Jones, Stephen 1995. Introduction. In: Janet Carsten \& Stephen Hugh-Jones (eds.) About the House: Lévi-Strauss and Beyond. Cambridge: Cambridge University Press, pp. 1-47.

Cowdell, Paul 2011. Belief in Ghosts in Post-War England. Diss. (PhD thesis). The University of Hertfordshire, United Kingdom. Available at http://uhra.herts.ac.uk/ handle/2299/7184, last accessed on May 4, 2016.

Derrida, Jacques 2006 [1993]. Specters of Marx: The State of the Debt, the Work of Mourning, and the New International. New York and London: Routledge.

Douglas, Mary 1966. Purity and Danger: An Analysis of the Concepts of Pollution and Taboo. London \& New York: Routledge.

Durkheim, Émile 1997 [1893]. The Division of Labour in Society. New York: The Free Press.

Goldstein, Diane E. \& Grider, Sylvia Ann \& Thomas, Jeannie Banks (eds.) 2007. Haunting Experiences: Ghosts in Contemporary Folklore. Logan, Utah: Utah State University Press, Available at http://digitalcommons.usu.edu/cgi/viewcontent.cg i? article=1017\&context=usupress_pubs, last accessed on May 4, 2016.

Hufford, David J. 2001. An Experience-Centered Approach to Hauntings. In: James Houran \& Rense Lange (eds.) Hauntings and Poltergeists: Multidisciplinary Perspectives. Jefferson, North Carolina \& London: McFarland and Company, pp. $18-40$.

Jöhncke, Steffen \& Raahauge, Kirsten Marie \& Steffen, Vibeke (eds.) 2015. Between Magic and Rationality: On the Limits of Reason in the Modern World. Copenhagen: Museum Tusculanum Press.

Latour, Bruno 2004. Why Has Critique Run out of Steam? From Matters of Fact to Matters of Concern. Critical Inquiry, Vol. 30, No. 2, pp. 225-248. http://dx.doi. org/10.1086/421123.

Raahauge, Kirsten Marie 2007. En Arhusantropologi. [Aarhus Anthropology.] Diss. (PhD thesis). Statens Byggeforskningsinstitut and Aalborg Universitet. Available at http://vbn.aau.dk/da/publications/en-aarhusantropologi\%28f62b58902a8f-11df-937b-000ea68e967b\%29.html, last accessed on May 11, 2016.

Raahauge, Kirsten Marie 2015. The Ghost in the Machine: Haunted Houses, Intense Sensations, and Residual Rationalities. In: Vibeke Steffen \& Steffen Jöhncke \& Kirsten Marie Raahauge (eds.) Between Magic and Rationality: On the Limits of Reason in the Modern World. Copenhagen: Museum Tusculanum Press, pp. 315-342.

Thomas, Jeannie Banks 2007. The Usefulness of Ghost Stories. In: D. E. Goldstein \& S. A. Grider \& J. B. Thomas (eds.) Haunting Experiences: Ghosts in Contemporary Folklore. Logan, Utah: Utah State University Press, pp. 25-59. Available at http://digitalcommons.usu.edu/cgi/viewcontent.cgi?article=1017\&context=usup ress_pubs, last accessed on May 4, 2016. 
Valk, Ülo 2006. Ghostly Possession and Real Estate: The Dead in Contemporary Estonian Folklore. Journal of Folklore Research, Vol. 43, No. 1, pp. 31-51. Available at http://www.jstor.org/stable/i291347, last accessed on June 21, 2016. 